\title{
Numerical research of heat and mass transfer at the ignition of system "fabric - combustible liquid - oxidant" by the local energy source
}

\author{
Dmitrii O. Glushkova ${ }^{a}$, Genii V. Kuznetsov and Pavel A. Strizhak \\ National Research Tomsk Polytechnic University, 634050 Tomsk, Russia
}

\begin{abstract}
A numerical research was executed for macroscopic regularities determination of heat and mass transfer processes under the conditions of phase transformation and chemical reaction at the ignition of vapour coming from fabrics impregnated by typical combustible liquid into oxidant area at the local power supply. Limit conditions of heterogeneous system "fabric - combustible liquid - oxidant" ignition at the heating of single metal particle was established. Dependences of ignition delay time on temperature and rates of local power source were obtained.
\end{abstract}

\section{Introduction}

Numerical investigations of heat and mass transfer processes at the ignition of solid [1-4], liquid [5-8] condensed substances and polymer materials $[9,10]$ by local energy source with limited power consumption (metallic and non-metallic particles, wires, cores, concentrate radiation flows and etc.) was held in recent years.

In power engineering and mechanical engineering at various technological processes products from fabric rather often can be applied to cleaning of surfaces, putting greasing, removal of surplus of greasing, etc. As a rule, such fabrics after corresponding technological processes have high fire danger.

The purpose of present work is numerical research of heat and mass transfer processes in system "fabric - combustible liquid - oxidant" and investigation of extreme ignition conditions for combustible vapors coming from fabric surfaces impregnated by liquid condensed substance under the local heating.

\section{Problem statement}

We considered physical and chemical processes in system "fabric - combustible liquid - oxidant" (Fig. 1). It was taken that at initial moment $(\tau=0)$ small particle heated to high temperature becomes in contact with fabric impregnated by combustible liquid (fuel). It volume fraction $(\varphi)$ was known. At local heating components of liquid start evaporating intensively. Combustible gas mixture is formed at the expense of a diffusive and convective heat and mass transfer in the oxidizer area. Generated

\footnotetext{
${ }^{a}$ Corresponding author: dmitriyog@tpu.ru
}

This is an Open Access article distributed under the terms of the Creative Commons Attribution License 4.0, which permits unrestricted use, distribution, and reproduction in any medium, provided the original work is properly cited. 


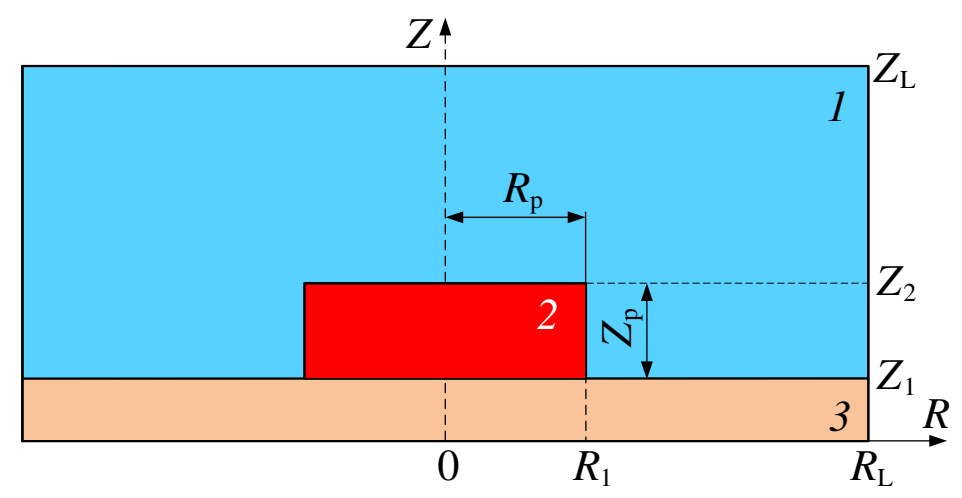

Figure 1. A scheme of the solution domain area at $\tau=0: 1-$ air, 2 - hot particle, 3 - fabric impregnated by liquid fuel.

gas mixture is heated by the hot particle energy. Ignition is happened at the critical temperature and concentration of combustible gas mixture.

Investigations were held for typical liquid fuels (gasoline, kerosene, diesel fuel) and widespread fabrics (wool, silk, flax). The steel particle in the shape of disk with small rates $R_{\mathrm{p}}$ and $Z_{\mathrm{p}}$ was chosen as a source of heat. We accepted two ignition conditions [11]:

1. The heat released as a result of gas oxidation reaction in air exceeds quantity of energy transferred from the particle to the substance and the gas mixture.

2. Temperature of gas mixture is higher than the initial temperature of the hot steel particle.

\section{Mathematical model}

Mathematical model (analog [1-10]) describe the interrelated processes of heat transfer in fabric, evaporation of combustible liquid, diffusive and convective heat and mass transfer and oxidation in the gas phase was represented by the system of non-stationary differential equations. It system with initial and boundary conditions was solved by the finite difference method. To solve difference analogs of differential equations the locally one-dimensional method was applied. Non-linear difference analogs of differential equations were solved by the iteration method. To solve one-dimensional differential equations the double sweep method with the implicit four-point scheme was applied. We selected no less that 400 knots of the difference net for each of the coordinates and used time step $10^{-6} \mathrm{~s}$.

The reliability of the obtained results was verified by the comparison with the experimental data. Besides check of the energy conservation law in the solution field was carried out according algorithm given in [5-8]. The error of the energy conservation law at change of initial temperature and the rates of a hot particle did not exceed $2.5 \%$.

The transition to the dimensionless variables $\left(R=r / z_{\mathrm{L}}, Z=z / z_{\mathrm{L}}, \tau=t / t_{\mathrm{m}}, \Theta=\left(T-T_{0}\right) /\left(t_{\mathrm{m}}-\right.\right.$ $\left.T_{0}\right)$ ) was done for the following scale values: characteristic size of solution area $z_{\mathrm{L}}=0.02 \mathrm{~m}$; time scale $t_{\mathrm{m}}=1 \mathrm{~s}$; temperature scale $T_{\mathrm{m}}=1000 \mathrm{~K}$.

\section{Results and discussion}

The numerical simulation was carried out for the following values of thermophysical and thermochemical parameters: air: $C=1006 \mathrm{~J} /(\mathrm{kg} \cdot \mathrm{K}), \rho=1.161 \mathrm{~kg} / \mathrm{m}^{3}, \lambda=0.026 \mathrm{~W} /(\mathrm{m} \cdot \mathrm{K})$; steel: $C=470 \mathrm{~J} /(\mathrm{kg} \cdot \mathrm{K}), \rho=7831 \mathrm{~kg} / \mathrm{m}^{3}, \lambda=49 \mathrm{~W} /(\mathrm{m} \cdot \mathrm{K}), Q_{\mathrm{c}}=205 \cdot 10^{3} \mathrm{~J} / \mathrm{kg}$; flax: $C=1580 \mathrm{~J} /(\mathrm{kg} \cdot \mathrm{K}), \rho=1500 \mathrm{~kg} / \mathrm{m}^{3}, \lambda=0.088 \mathrm{~W} /(\mathrm{m} \cdot \mathrm{K})$; 
Table 1. Dimensionless ignition delay time versus dimensionless initial particle temperature $\Theta_{\mathrm{p}}$.

\begin{tabular}{|l|c|c|c|c|c|c|c|}
\hline$\Theta_{\mathrm{p}}$ & 1.50 & 1.45 & 1.40 & 1.35 & 1.30 & 1.25 & 1.20 \\
\hline$\tau_{\mathrm{d}}^{*}$ & 0.031 & 0.041 & 0.063 & 0.099 & 0.152 & 0.228 & no ignition \\
\hline$\tau_{\mathrm{d}}^{* *}$ & 0.030 & 0.039 & 0.058 & 0.081 & 0.127 & 0.187 & no ignition \\
\hline
\end{tabular}

$\tau_{\mathrm{d}}^{*}$ is dimensionless ignition delay time obtained at the numerical Research;

$\tau_{\mathrm{d}}^{* *}$ is dimensionless ignition delay time obtained at the approximation of

experimental research results.

Table 2. Dimensionless ignition delay time versus dimensionless rates of energy source $R_{\mathrm{p}}$ at $Z_{\mathrm{p}}=0.4, \Theta_{\mathrm{p}}=1.35$.

\begin{tabular}{|l|l|l|l|l|l|}
\hline$R_{\mathrm{p}}$ & 0.150 & 0.175 & 0.200 & 0.225 & 0.250 \\
\hline$\tau_{\mathrm{d}}^{*}$ & 0.102 & 0.094 & 0.090 & 0.089 & 0.087 \\
\hline$\tau_{\mathrm{d}}^{* *}$ & 0.095 & 0.091 & 0.088 & 0.087 & 0.086 \\
\hline$\tau_{\mathrm{d}}^{* * * *}$ & 0.087 & 0.080 & 0.076 & 0.075 & 0.073 \\
\hline
\end{tabular}

$\tau_{\mathrm{d}}^{*}$ is dimensionless ignition delay time of fabric impregnated by gasoline;

$\tau_{\mathrm{d}}^{* *}$ is dimensionless ignition delay time of fabric impregnated by kerosene;

$\tau_{\mathrm{d}}^{* * *}$ is dimensionless ignition delay time of fabric impregnated by diesel fuel.

silk: $\quad C=1386 \mathrm{~J} /(\mathrm{kg} \cdot \mathrm{K}), \quad \rho=1560 \mathrm{~kg} / \mathrm{m}^{3}, \quad \lambda=0.06 \mathrm{~W} /(\mathrm{m} \cdot \mathrm{K}) ; \quad$ wool: $\quad C=1721 \mathrm{~J} /(\mathrm{kg} \cdot \mathrm{K})$, $\rho=1320 \mathrm{~kg} / \mathrm{m}^{3}, \quad \lambda=0.052 \mathrm{~W} /(\mathrm{m} \cdot \mathrm{K}) ; \quad$ gasoline: $\quad C=2060 \mathrm{~J} /(\mathrm{kg} \cdot \mathrm{K}), \quad \rho=751 \mathrm{~kg} / \mathrm{m}^{3}, \quad \lambda=$ $0.116 \mathrm{~W} /(\mathrm{m} \cdot \mathrm{K}), \quad Q_{\mathrm{e}}=29.4 \cdot 10^{3} \mathrm{~J} / \mathrm{kg}, \quad M=100 \mathrm{~kg} / \mathrm{kmol} ; \quad$ gasoline $\quad$ vapors: $\quad C=2280 \mathrm{~J} /$ $(\mathrm{kg} \cdot \mathrm{K}), \rho=2.5 \mathrm{~kg} / \mathrm{m}^{3}, \lambda=0.027 \mathrm{~W} /(\mathrm{m} \cdot \mathrm{K}), Q_{\mathrm{o}}=45 \cdot 10^{6} \mathrm{~J} / \mathrm{kg}, E=130 \cdot 10^{3} \mathrm{~J} / \mathrm{mole}, k_{0}=7 \cdot 10^{6} \mathrm{~s}^{-1}$, $\beta=0.0012 \mathrm{~K}^{-1}, \quad D=14.12 \cdot 10^{-6} \mathrm{~m}^{2} / \mathrm{s} ; \quad v=1.21 \cdot 10^{9} \mathrm{~m}^{2} / \mathrm{s} ; \quad$ kerosene: $\quad C=2190 \mathrm{~J} /(\mathrm{kg} \cdot \mathrm{K})$, $\rho=885 \mathrm{~kg} / \mathrm{m}^{3}, \lambda=0.117 \mathrm{~W} /(\mathrm{m} \cdot \mathrm{K}), Q_{\mathrm{e}}=26.1 \cdot 10^{3} \mathrm{~J} / \mathrm{kg}, M=166.2 \mathrm{~kg} / \mathrm{kmol}$; kerosene vapors: $C=$ $2370 \mathrm{~J} /(\mathrm{kg} \cdot \mathrm{K}), \rho=2.8 \mathrm{~kg} / \mathrm{m}^{3}, \lambda=0.028 \mathrm{~W} /(\mathrm{m} \cdot \mathrm{K}), Q_{\mathrm{o}}=43.8 \cdot 10^{6} \mathrm{~J} / \mathrm{kg}, E=190 \cdot 10^{3} \mathrm{~J} / \mathrm{mole}, k_{0}=$ $7 \cdot 10^{7} \mathrm{~s}^{-1}, \beta=0.00096 \mathrm{~K}^{-1}, D=8.07 \cdot 10^{-6} \mathrm{~m}^{2} / \mathrm{s} ; v=0.66 \cdot 10^{9} \mathrm{~m}^{2} / \mathrm{s}$; diesel fuel: $C=2980 \mathrm{~J} /(\mathrm{kg} \cdot \mathrm{K})$, $\rho=887.7 \mathrm{~kg} / \mathrm{m}^{3}, \lambda=0.1169 \mathrm{~W} /(\mathrm{m} \cdot \mathrm{K}), \quad Q_{\mathrm{e}}=25 \cdot 10^{3} \mathrm{~J} / \mathrm{kg}, \quad M=150 \mathrm{~kg} / \mathrm{kmol}$; diesel fuel vapors: $C=3230 \mathrm{~J} /(\mathrm{kg} \cdot \mathrm{K}), \rho=3.1 \mathrm{~kg} / \mathrm{m}^{3}, \lambda=0.029 \mathrm{~W} /(\mathrm{m} \cdot \mathrm{K}), Q_{0}=42 \cdot 10^{6} \mathrm{~J} / \mathrm{kg}, E=250 \cdot 10^{3} \mathrm{~J} / \mathrm{mole}, k_{0}=$ $9 \cdot 10^{8} \mathrm{~s}^{-1}, \beta=0.0009 \mathrm{~K}^{-1}, D=5.29 \cdot 10^{-6} \mathrm{~m}^{2} / \mathrm{s} ; v=1.15 \cdot 10^{9} \mathrm{~m}^{2} / \mathrm{s}$.

Particle rates $R_{\mathrm{p}}=0.15-0.25, Z_{\mathrm{p}}=0.15-0.25$; fabric thicknesses $Z_{1}=0.15$; domain solution rates $R_{\mathrm{L}}=Z_{\mathrm{L}}=1$; particle initial temperature $\Theta_{\mathrm{p}}=1-1.5$; fabric and oxidant initial temperature $\Theta_{0}=0.3$.

Nomenclature were used: $C$ is specific heat capacity; $D$ is Coefficient of diffusion; $E$ is Activation energy; $k_{0}$ is Preexponential factor; $Q_{\mathrm{c}}$ is heat of particle material crystallization; $Q_{\mathrm{e}}$ is heat of liquid fuel evaporation; $Q_{\mathrm{o}}$ is Heat of oxidation reaction of fuel vapors in air; $\Theta_{0}$ is dimensionless initial temperature of air and fabric; $\Theta_{\mathrm{p}}$ is dimensionless initial temperature of particle; $\beta$ is coefficient of thermal expansion; $\lambda$ is thermal conductivity; $\rho$ is density; $v$ is coefficient of kinematic viscosity; $\varphi$ is volume fraction.

At numerical simulation the volume fraction value $\varphi$ was varied within the range from $5 \%$ to $50 \%$. It was established that the stable ignition of the heterogeneous system take place under fabric highporous structure (up to $30-40 \%$ of the heterogeneous system mass is the liquid condensed substance). So regardless of the local source temperature $\Theta_{\mathrm{p}}$ and its rates $R_{\mathrm{p}}$ and $Z_{\mathrm{p}}$, it can be concluded that the requirement $\varphi>30 \%$ should be accomplished for ignition realization in the system "fabric combustible liquid - oxidant".

The dependencies of ignition delay time $\tau_{\mathrm{d}}$ on initial temperature $\Theta_{\mathrm{p}}$ and characteristic rate $R_{\mathrm{p}}$ (with fixed $Z_{\mathrm{p}}$ ) of metallic particle for fabrics impregnated by different combustible liquids (gasoline, kerosene, diesel fuel) are present on the Tables 1 and 2. We used developed mathematical model of process for calculation these characteristics. Earlier it was established $[5,6]$ that correlation of the square of local power source contact with the condensed substance and square of gas medium determined the 
possibility of ignition conditions realization. Therefore the particle size $R_{\mathrm{p}}$ determined its contacting area with fabric was varied.

Table 1 shows the good correlation of executed numerical and experimental investigation results. Deviations of experimental values $\tau_{\mathrm{d}}$ rather corresponding calculated values do not exceed $18 \%$. With temperature increasing $\Theta_{p}$ these deviations are reduced to $3.2 \%$ (at $\Theta_{p}=1.50$ ). It feature can be explained by the fact that we used known values (from reference books) of oxidation reactions kinetic parameters $\left(k_{0}=\right.$ const and $E=$ const $)$ at the simulation. For approximation the theoretical models to real applications it is advisable to take into account the dependence of $k_{0}$ and $E$ on the temperature. It is known $[12,13]$ that this feature is important at the local heating of small droplets, thin films and large amounts of liquid condensed substances by sources with limited power consumption. The similar task requires special consideration. Therefore physical and chemical processes features associated with dependencies $k_{0}=f\left(\Theta_{\mathrm{p}}\right)$ and $E=f\left(\Theta_{\mathrm{p}}\right)$ not analyzed in this article.

Dependences of $\tau_{\mathrm{d}}=f\left(R_{\mathrm{p}}\right)$ (Table 2) illustrate that the source rates (especially $R_{\mathrm{p}}$ ) are less impact on integrated ignition characteristics compared to $\Theta_{\mathrm{p}}$ (Table 1). Therefore even a relatively small area of particle contact with the impregnated fabric is sufficient to achieve the high velocities of the phase transition and the oxidation reaction acceleration (when $\Theta_{p}>1$ ).

The difference between ignition integrated characteristics of fabric impregnated by some kinds of combustible liquids (gasoline, kerosene, diesel fuel) was established as a result of numerical investigations of ignition processes in heterogeneous system "fabric - combustible liquid - oxidant". These characteristics correspond well to the results of experimental investigations of ignition process in homogeneous system (liquid fuels) [14]. It was determined that the ignition delay time for systems with gasoline vapors are minimal and for systems with diesel fuel vapors are maximal (Table 2) under otherwise equal conditions. Values of $\tau_{\mathrm{d}}$ for systems with kerosene vapors have some intermediate values (Table 2). It is caused by the evaporation regularities (the phase transition temperature, kinetics, chemical composition, etc.) for different fuels [14].

Besides it was established that realization of three ignition modes is possible for the system "fabric combustible liquid - oxidant" during the local heating. However in contrast to the homogeneous liquid fuels [5-8], the mode when zone of exothermal reaction formulates near the lateral sides of ignition source (Fig. 2) is the most typical at variation of $\Theta_{\mathrm{p}}, R_{\mathrm{p}}, Z_{\mathrm{p}}, \varphi$ in wide ranges.

It can be explained according the fact that the contact square of the heating source with a substance in the system "fabric - combustible liquid - oxidant" is less than in the system "combustible liquid - oxidant" (particle immersion happens in liquids and square of heat sink into near-surface layer increases). Therefore the local energy source cools down more intensively at interaction with liquid in comparison with the system "fabric - combustible liquid - oxidant".

\section{Conclusions}

The necessary $(\varphi>30 \%)$ and sufficient $\left(\Theta_{p}>1\right)$ ignition conditions of heterogeneous system - widely used fabrics (wool, silk, flax) impregnated by typical combustible liquids (gasoline, kerosene, diesel fuel) under the local heating were established as a result of numerical investigations. The impact extents of temperature and rates of local energy source and combustible liquid volume fraction in fabric on the ignition integrated characteristics were determined. It was established that the values of $\Theta_{p}$ and $\varphi$ have dominant role in combustion process.

Investigation results allow making conclusion about the high possibility of ignition conditions realization at cooperation of typical local heat sources with heterogeneous structures, in particular, fabrics impregnated by liquid condensed substances. In the case of a small fabric thicknesses and its high porosity the ignition process is characterized by small $\left(\tau_{\mathrm{d}}<0.1\right)$ ignition delay time close to similar characteristic for homogeneous liquid fuels. 
Thermophysical Basis of Energy Technologies

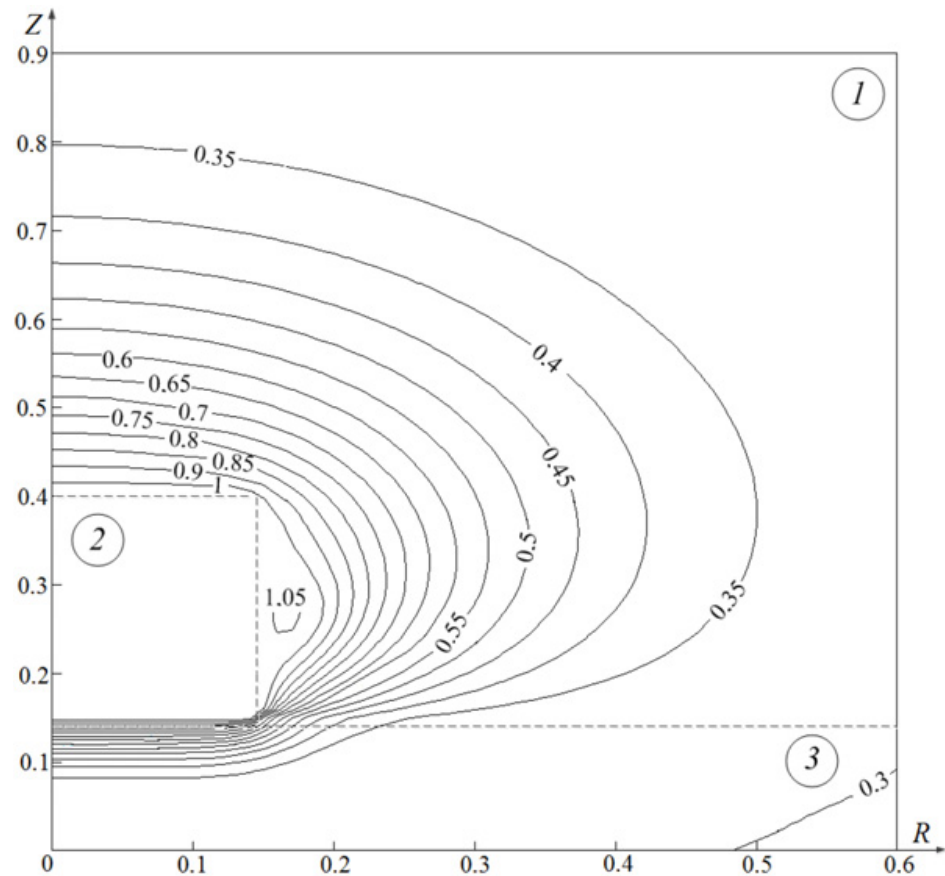

(a)

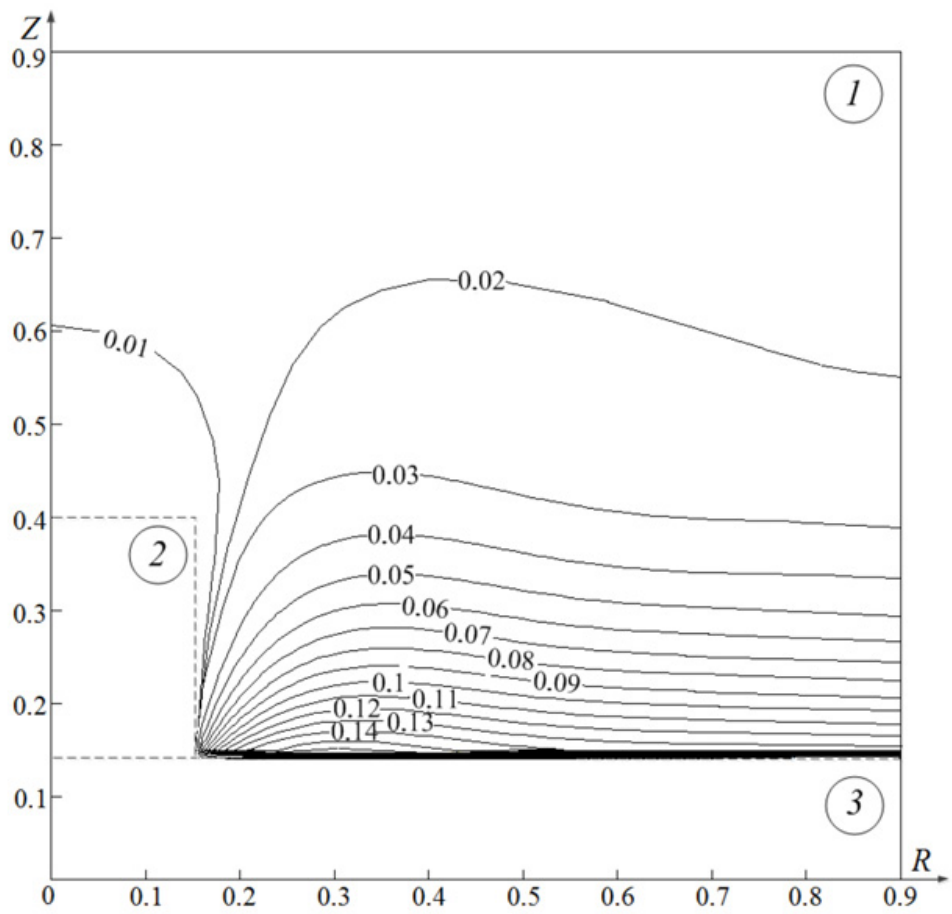

(b)

Figure 2. Isotherms $\Theta$ (a) and isolines of fuel concentration $C_{\mathrm{f}}$ (b) at the system "steel particle - the woolen fabric impregnated with kerosene - air" at ignition $\left(\tau_{\mathrm{d}}=0.314\right)$ for $\Theta_{\mathrm{p}}=1.15, R_{\mathrm{p}}=0.15, Z_{\mathrm{p}}=0.25, \varphi=0.35: 1-$ gas mixture, 2 - hot particle, 3 - fabric impregnated with combustible liquid substance. 
The reported study was supported by the Grant of the President of the Russian Federation (MK-2391.2014.8).

\section{References}

[1] G.V. Kuznetsov, G.Y. Mamontov, G.V. Taratushkina, Russ. J. Phys. Chem. B 23, 67 (2004)

[2] A.V. Zakharevich, V.T. Kuznetsov, G.V. Kuznetsov, V.I. Maksimov, Combust. Explos., Shock Waves 44, 543 (2008)

[3] D.O. Glushkov, G.V. Kuznetsov, P.A. Strizhak, Russ. J. Phys. Chem. B 5, 1000 (2011)

[4] D.O. Glushkov, G.V. Kuznetsov, P.A. Strizhak, Russ. J. Phys. Chem. B 7, 269 (2013)

[5] G.V. Kuznetsov, P.A. Strizhak, Combust. Explos., Shock Waves 46, 683 (2010)

[6] G.V. Kuznetsov, P.A. Strizhak, Russ. J. Phys. Chem. B 4, 249 (2010)

[7] O.V. Vysokomornaya, G.V. Kuznetsov, P.A. Strizhak, Russ. J. Phys. Chem. B 5, 668 (2011)

[8] D.O. Glushkov, P.A. Strizhak, Adv. Mech. Eng. 2014, 269321 (2014)

[9] D.O. Glushkov, P.A. Strizhak, J. Eng. Thermophys. 21, 69 (2012)

[10] M.M. Grigoryeva, G.V. Kuznetsov, P.A. Strizhak, J. Eng. Thermophys. 20, 192 (2011)

[11] V.N. Vilyunov, V.E. Zarko, Ignition of solids (Elsevier, Amsterdam, 1989)

[12] D.A. Frank-Kamenetsky, Diffusion and heat transfer in chemical kinetics (Plenum, New York, 1969)

[13] P. Dagaut, M. Cathonnet, Prog. Energ. Combust. 32, 48 (2006)

[14] G.V. Kuznetsov, P.A. Strizhak, J. Eng. Thermophys. 17, 244 (2008) 